\title{
Comparative Evaluation of the Efficacy of Chlorhexidine, Sodium Hypochlorite, the Diode Laser and Saline in Reducing the Microbial Count in Primary Teeth Root Canals - An In Vivo Study
}

\author{
Vidhi Walia ${ }^{1}$, Mousumi Goswami ${ }^{1}$, Shivesh Mishra ${ }^{2}$, Nidhi Walia ${ }^{3}$, Divya Sahay ${ }^{4}$ \\ ${ }^{1}$ Department of Pedodontics and Preventive Dentistry, ITS Dental College, Hospital and Research Center, Greater Noida, \\ India \\ ${ }^{2}$ Department of Periodontology and Oral Implantology, ITS Dental College, Hospital and Research Center, Greater Noida, \\ India \\ ${ }^{3}$ Department of Prosthodontics, ITS Dental College, Hospital and Research center, Greater Noida, India \\ ${ }^{4}$ Department of Microbiology, ITS Dental College, Hospital and Research center, Greater Noida, India
}

\section{*Correspondence to \\ Vidhi Walia, \\ G-16, PreetVihar, Delhi-110032 Tel: +919811578261 \\ Email: vidhi30libran@gmail.com}

Published online October 1, 2019

\begin{abstract}
Introduction: One of the primary goals of pulpectomy is to decrease the sum total of microorganisms and disinfect the tooth root canal system. To achieve this, mechanical preparation, irrigation, disinfection and obturation of the root canal is necessary. The present study was set out to evaluate the difference in the antibacterial efficacy of primary teeth root canals either irrigated with chlorhexidine, saline, and sodium hypochlorite or irradiated with a soft tissue diode laser (980 nm, Photon Plus, Zolar Tech \& Mfg Co. Inc, Ontario, Canada).

Methods: Sixty primary teeth of children requiring pulpectomy were divided into 4 groups of 15 each, group 1 ( $2 \%$ chlorhexidine), group 2 ( $1 \%$ sodium hypochlorite), group 3 (laser irradiation) and group 4 (saline). Pulp tissue was extirpated from the canals and the samples were collected using sterile absorbent paper points. After cleaning and shaping, the root canals of the teeth in each group were irrigated using sodium hypochlorite, chlorhexidine, and saline or were irradiated with the laser. The samples were obtained again and sent for microbiological examination.

Results: The colony-forming unit (CFU) counts from pre-disinfection sample served as a baseline for comparisons throughout the study. The mean bacterial colony counts of all the isolated bacteria reduced after irrigation or irradiation. Intergroup comparisons showed no significant difference when groups 1,2 , and 3 were compared to each other $(P>0.05)$. However, a significant difference was seen when groups $1,2,3$ were compared to group $4(P<0.05)$.

Conclusion: Two percent chlorhexidine, $1 \%$ sodium hypochlorite and laser irradiation succeeded in reducing the root canal infection. Hence, diode laser irradiation may be a possible supplement to existing protocols for disinfecting the root canal system.

Keywords: Pulpectomy; Chlorhexidine; Sodium hypochlorite; Diode laser.
\end{abstract}

\section{Introduction}

Complete debridement and disinfection of pulpal space are considered to be a prerequisite for the eternal success of the endodontic procedure. Even after meticulous mechanical preparation, residual pulp tissue, dentin debris and bacteria may remain inside the irregularities of the tooth root canals. ${ }^{1}$ Moreover, it is assumed that any left-out pulp tissue in the root canal system can provide nutrition to the bacterial species. ${ }^{2}$

The endodontic treatment of primary teeth is truly challenging because of the anatomical complexities like accessory foramina in furcal areas and aberrant morphology of their root canals. ${ }^{3}$ In addition to the accessory canals, exposure of dentinal tubules as a result of physiological root resorption can also lead to structural alterations and greater permeability of the root surface to various microbial toxins. ${ }^{4,5}$ The bacterial profile of root canals of human teeth associated with necrotic pulp and periapical lesions is enormous as well as extensive. This point has already been proven $^{6-9}$; however, there are only a few studies concerned with the bacterial diversity in the root canal of human primary teeth. ${ }^{6}$ Some studies report Streptococci as the predominant microorganism, ${ }^{7,8,10,11}$ whereas others report staphylococci or Escherichia coli

Please cite this article as follows: Walia V, Goswami M, Mishra S, Walia N, Sahay D. Comparative evaluation of the efficacy of chlorhexidine, sodium hypochlorite, the diode laser and saline in reducing the microbial count in primary teeth root canals - an in vivo study. I Lasers Med Sci. 2019;10(4):268-274. doi:10.15171/jlms.2019.44. 
as the most ubiquitous microorganism in the root canal system of primary teeth. ${ }^{12,13}$ Furthermore, an in vivo study reported Enterococcus faecalis and E. coli as the predominant bacteria in the samples tested. ${ }^{10}$

Nonetheless, the inhabitants of root canals in primary teeth with necrotic pulp and periapical lesions may be aerobic and anaerobic bacteria or facultative anaerobes. ${ }^{6}$ Enterococci have also been suspected in endodontic infections. Among the different enterococci species, $E$. faecalis is the most common species which is isolated from the human teeth root canals. It constitutes a very little proportion of the bacterial species isolated from the root canals of human teeth. ${ }^{14,15}$ Cogulu et al found only $18 \%$ E. faecalis from 45 necrotic primary teeth using both the culture and polymerase chain reaction method. Moreover, ex vivo and clinical trials have shown that mechanical instrumentation leaves considerable portions of the root canal walls uninstrumented or untouched. ${ }^{16}$ Taking into account the anatomical complexities in teeth and root canal microbiota, the irrigation of the root canals is an extremely important addition to mechanical preparation. Irrigants help in dislodging the loosened and suspended debris from canal space and dissolving organic and inorganic components of the smear layer. ${ }^{17}$ Over the years, several irrigants such as sodium hypochlorite $(\mathrm{NaOCl})$, hydrogen peroxide, 17\% EDTA, citric acid and MTAD have been recommended for chemo-mechanical canal preparation. $2 \%$ chlorhexidine gluconate ( $\mathrm{CHX}$ ) has been suggested as an alternative irrigating solution and is also associated with the phenomenon of substantivity; that is, it attaches to the surrounding adjacent tissues and is then released again slowly over an extended period of time. ${ }^{18}$ Apart from inherent flushing activity, irrigants should also serve as a bactericidal agent, tissue solvent and lubricant. ${ }^{17}$ The bactericidal effect of the irrigating solutions is limited in the dentinal tubules due to narrow diameter of tubules and high surface tension of the irrigating solutions. This restricts the penetration of irrigating solutions to a greater distance through the tubules. ${ }^{19,20}$ Even the most ideal available irrigating solution, namely sodium hypochlorite, is not able to completely sterilize the root canals. ${ }^{21}$ Therefore, to complement the conventional treatment, additional methods have been proposed to overcome the limitations of incomplete elimination of bacteria from the root canals.

The use of lasers to sterilize the root canals is a recent advancement. Inherent properties of laser irradiation like local intensity enhancement, light scattering and attenuation, permit deeper light penetration into the dentinal tubules. This deeper light penetration is responsible for the stronger bactericidal effect of laser irradiation inside the dentinal tubules. ${ }^{22}$

Existing laser systems for use in root canal disinfection are Nd:YAG, argon and diode lasers, CO2 Er:YAG lasers or photodynamic therapy. Photodynamic therapy is a technique employed for root canal disinfection using a photosensitizer; that produces singlet oxygen out of molecular oxygen (3O2) and other free radicals when exposed to laser light which in turn causes damage to the bacterial membrane and its DNA.,23,24 The soft tissue dental Diode laser is a compact and portable device which is used in various areas of dentistry. The diode laser emits radiation within the visible (mostly $660 \mathrm{~nm}$ ) and infrared $\left(810\right.$ to $980 \mathrm{~nm}$ ) range of the electromagnetic spectrum. ${ }^{24}$ Moritz et al introduced its use for disinfecting the root canal system with the help of a thin and flexible fiber delivery system. The fine diameters of optic fibers (200$320 \mu \mathrm{m})$ permit effective distribution of laser light in the root canal system to help with the lowering of microbial contamination. ${ }^{21}$

Most of the available literature is about in vitro studies performed on permanent teeth, with a scarcity of literature involving primary teeth. Also, in vivo conditions cannot be accurately simulated in the laboratory environment. Therefore, the present study was undertaken in primary teeth, as they contain a much broader spectrum of pathogens with deeper penetration into the tubules compared to any in vitro systems.

The purpose of this study was to compare the efficiency of chlorhexidine, sodium hypochlorite, diode lasers and normal saline in reducing the microbial count of the primary teeth root canals.

\section{Materials and Methods}

The sample size was calculated on the basis of a pilot study, which consisted of 12 microbiological samples taken from the primary teeth root canals requiring pulpectomy (3 in each group). The samples of the pilot study were not included in the final sample size and statistical analysis. With the data obtained from the pilot study (with a 95\% confidence interval and the statistical test power of 80\%), the sampling of patients was done and the probability of making a type one error $(\alpha)$ was set at 0.05 .

The eligible participants for this study were selected from children of both genders aged between 3 and10.They were referred for dental treatment to the Department of Pediatric dentistry, I.T.S Dental College, Hospital and Research Centre, Greater Noida. The children who presented with any systemic illness or medically compromising conditions or had consumed antibiotics within the last 2 months or had any history of previous endodontic treatment in the same tooth were excluded. The primary teeth showing any signs of internal root resorption radiographically were also not considered for the study.

The children with the history of spontaneous pain, a clinically non-vital tooth with pus discharge, the teeth with continuous bleeding after the amputation of the coronal pulp tissue, and those with sufficient coronal structure were included. Radiographically, the teeth showing interradicular or periapical radiolucency and with less than two-thirds of root resorption were enrolled 
for the study. The primary teeth with pulpal caries showing pathological external root resorption were included in the study.

A total of 60 primary teeth from 60 children were selected and divided into 4 groups of 15 each. For randomization, the patients were asked to choose a ball from a box containing four differently colored balls (red, blue, yellow, green). As a result, the following groups were created in the present study:

1. Group 1: Red ball - Root canal irrigation with 2\% chlorhexidine (Dentochlor, Ammdent,2\% Chlorhexidine solution)

2. Group 2: Blue ball - Root canal irrigation with $1 \%$ sodium hypochlorite (positive control)(Prime dental products Pvt. Ltd.)

3. Group 3: Yellow ball - Root canal irradiated with a diode laser

4. Group 4: Green ball - Root canal irrigation with saline $(\mathrm{NaCl}, 0.9 \%$ sodium chloride intravenous infusion IP, BI Braun group company).

Before starting the procedure, the patients were asked to rinse their mouth with $5 \mathrm{~mL}$ of povidone iodine for 30 seconds. The procedure was performed by a single operator. After local anesthesia, the rubber dam was placed. A high-speed handpiece with a sterilized round bur was used to remove all caries and access the tooth root canal under constant irrigation with sterile distilled water. Prior to the collection of any pre-disinfection sample, a sterile barbed broach (21 mm ISO 020 Spirocolorinox, Dentsply Maillefer, Ballaigues, Switzerland) was inserted into the tooth root canal for the extirpation of pulp to the working length, which was predetermined from a preoperative intraoral periapical $\mathrm{x}$-ray.

The absorbent paper point (ISO 15, Dentsply Maillefer, Ballaigues, Switzerland) was introduced into the root canal and was allowed to rest. After 1 minute, the paper point was taken out and was placed directly into the sterile sample collection container containing $200 \mu \mathrm{L}$ nutrient broth medium.

For the purpose of standardization, the samples were taken from the palatal root canal and the distal root canal of the primary maxillary molars and the primary mandibular molars respectively.

Shaping and cleansing the canals were done with sterile Kerr files and Hedstrom files. Then, the root canals were disinfected using $20 \mathrm{~mL}$ each of chlorhexidine (2\%), sodium hypochlorite (1\%) and saline in groups 1, 2 and 4 respectively. The teeth in group 3 were irradiated with flexible glass fibre tips of a $200-\mu \mathrm{m}$ diameter of a ZOLAR diode laser 4 times for a period of 5 seconds at the inbuilt mode 'root canal sterilization'.

The fiber was introduced to $4 \mathrm{~mm}$ short of the radiographic apex (eg. If radiographic apex was $12 \mathrm{~mm}$ then the fiber was put in till $8 \mathrm{~mm}$ ). The laser fiber was applied from the apical to coronal ends of the root canal under continuous recessing circling movements. A gap of 20 seconds was given between the 2 laser cycles of 5 seconds each. The disinfection protocol used for laser irradiation in this in vivo study was an adaptation of the method used by Safan et $\mathrm{al}^{25}$ and Kaiwar et $\mathrm{al}^{26}$ in their respective in vitro studies. The patient and the operator both wore the protective eyewear during laser irradiation.

The same technique used with the pre-disinfection samples was also used to collect the post-disinfection samples. Both the samples were then transported to a microbiological laboratory.

The microbiological culturing was carried out in the Department of Microbiology, ITS Dental College, Greater Noida. In the laboratory, the collected samples of all the groups, inoculated in nutrient broth, were vortexed and then incubated at $37^{\circ} \mathrm{C}$ for 2 hours. $0.01 \mathrm{ml}$ of the sample was then plated via a calibrated loop on blood agar and UTI agar plates (HiMedia Lab Pvt. Ltd., India). The agar plates were then incubated at $37^{\circ} \mathrm{C}$ for $24-48$ hours and counted for the growth of bacterial isolates. The count per millilitre of diluted broth was calculated and multiplied by the dilution factor. Each isolate was distinguished using standard conventional techniques which included gram staining and biochemical tests.

\section{Statistical Analysis}

Statistical analyses were performed using the Wilcoxon signed ranks test, Mann-Whitney U test, and one-way ANOVA. All analyses were conducted using the Statistical Package for the Social Sciences (SPSS) version 21.0. The five percent level of significance was used (i.e. $P$ value $<.05$ was considered statistically significant).

\section{Results}

The aerobic and facultative anaerobic microorganisms were quantified in 60 primary teeth. A range of bacteria were isolated from the chosen primary teeth root canals, including Escherichia coli (20\%), Staphylococcus (19\%), Streptococcus (16\%), E. faecalis (17\%), Neisseria (10\%), Pseudomonas (6\%), Candida, Klebsiella pneumonia, Enterococcus other than E. faecalis, Enterobacter aerogenes, micrococci and diphtheroids (see Figure 1).

The colony-forming unit (CFU) counts from the predisinfection sample served as a baseline for comparison throughout the study. It was seen that the mean bacterial colony counts of all the isolated bacteria reduced considerably after irrigation or laser irradiation. The Wilcoxon signed ranks test confirmed the reduction of colony counts in all the four groups. A significant difference was seen in the pre- and post-disinfection samples.

Intergroup comparisons were done using the Mann Whitney U test, which showed no significant difference when groups 1, 2, and 3 were compared to each other. However, a significant difference was seen when groups 1, 2, 3 were compared to group 4 (Table 1).

The percentage reduction in the CFU count for Group 


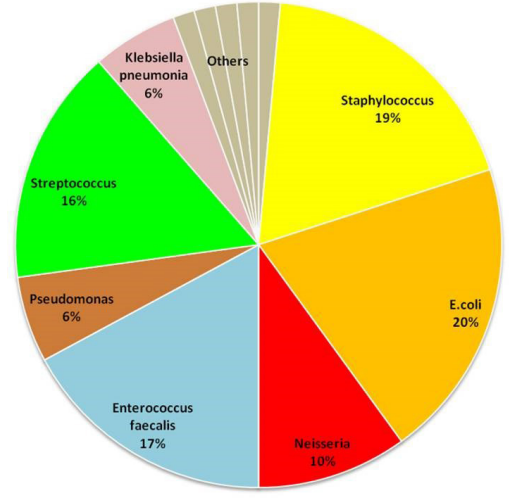

Figure 1. The Percentages of the Most Common Bacteria Found in the study.

Table 1. Intergroup Comparisons Using the Mann-Whitney U Test

\begin{tabular}{lccc}
\hline Group & N & Mean Rank (\% Reduction) & $\boldsymbol{P}$ Value \\
\hline $\begin{array}{l}\text { 2\% Chlorhexidine } \\
\text { 1\% Sodium hypochlorite }\end{array}$ & 15 & 16.53 & 0.409 \\
$\begin{array}{l}\text { 2\% Chlorhexidine } \\
\text { Diode Laser }\end{array}$ & 15 & 14.47 & \\
$\begin{array}{l}\text { 2\% Chlorhexidine } \\
\text { Saline }\end{array}$ & 15 & 13.27 & 0.175 \\
$\begin{array}{l}\text { 1\% Sodium hypochlorite } \\
\text { Diode Laser }\end{array}$ & 15 & 9.33 & 0.000 \\
$\begin{array}{l}\text { 1\% Sodium hypochlorite } \\
\text { Saline }\end{array}$ & 15 & 16.57 & 0.442 \\
$\begin{array}{l}\text { Diode Laser } \\
\text { Saline }\end{array}$ & 15 & 20.73 & \\
\hline
\end{tabular}

$1(96.62 \%)$ was maximum followed by groups $2(93.52 \%)$, $3(84.2 \%)$ and $4(56.83 \%)$ respectively (Figure 2$)$.

\section{Discussion}

In the last few years, there has been a shift in the pattern of root canal treatment in human primary teeth. Owing to the nature of the endodontic infections and peculiarities of these teeth, it is suggested that the mechanical instrumentation alone is not able to create a bacteria-free root canal system. ${ }^{27}$

Micro-computed tomography scans revealed that more than $35 \%$ of the root canal surfaces including isthmi, canal fins and cul-de-sacs remained uninstrumented, regardless of the instrumentation technique used. ${ }^{28}$ Hence, irrigation is an indispensable part of root canal debridement as it allows for cleaning beyond what might be achieved by mechanical root canal instrumentation alone. Irrigation with agents without antibacterial properties like saline only removes debris. However, the mechanical effects of any irrigants are generated by the back and forth flow of the irrigating solution during cleaning and shaping the infected root canals, significantly reducing the bacterial load. ${ }^{17}$

Several solutions have been used in root canal therapy

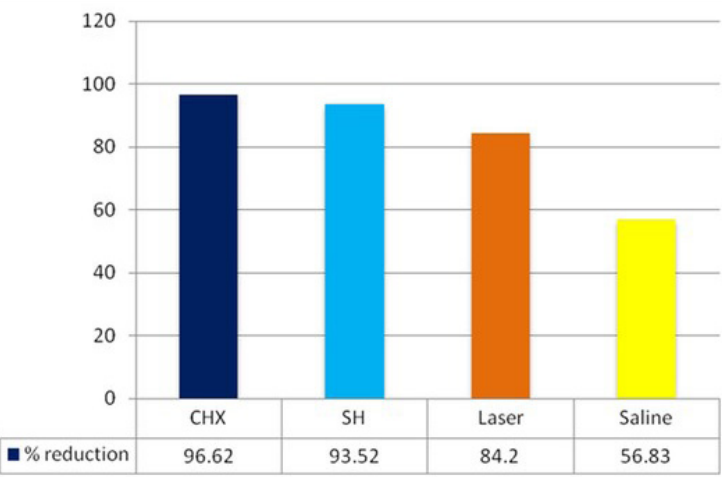

Figure 2. Percentage Reduction in the CFU Count.

to attain the required chemical effect since sodium hypochlorite was suggested by Walker in $1936 .{ }^{27}$ Sodium hypochlorite was used in the present study as the gold standard as it is the most universally preferred irrigant in the pulp therapy for primary teeth. However, there is no consensus in the present literature regarding its optimum concentration, which ranges from $0.5 \%$ to $5.25 \%{ }^{1}$ When anti-bacterial activity of different concentrations of $\mathrm{NaOCl}$, i.e. $1 \%, 2.5 \%$, and $5 \%$, was compared, no significant difference was seen in the decrease of the microbial population in root canal post irrigation and instrumentation. ${ }^{29}$ In the present study, $1 \%$ sodium hypochlorite was capable of reducing the colony counts of the microorganisms found in the pre-disinfection sample.

Chlorhexidine is a powerful antiseptic and is extensively used as aqueous solutions of $0.1 \%$ to $0.2 \%$ in chemical plaque control. However, $2 \%$ concentration of chlorhexidine is generally recommended in endodontic literature for the purpose of root canal irrigation. ${ }^{30}$ In this study, Chlorhexidine demonstrated a broad spectrum antimicrobial action, which is similar to the results of the previous studies. ${ }^{18,30,31}$ In the previous studies, minimal or no difference was observed when antimicrobial efficacy of $\mathrm{NaOCl}$ and $2 \% \mathrm{CHX}$ against the root canal infection was compared. ${ }^{32,33}$ This is in accordance with this study as $2 \%$ chlorhexidine and $1 \%$ sodium hypochlorite showed no statistically significant difference in the reduction of the bacterial colonies (see Table 1).

The standards of endodontics have constantly been raised in the last 25 years by practitioners' researches and their interests. Most of the scientists believe that the development of lasers is the most exciting achievement in endodontic treatment. ${ }^{20}$

Dental lasers can be used in various endodontic treatments like pulpotomy in primary teeth and the disinfection of the root canal system. AAPD also recognizes the use of lasers as an alternative method for providing root canal disinfection in infants, children and adolescents. $^{34}$

Prospective merit of lasers in the medical or dental 
field depends on the particular properties of the kind of laser and the specific target tissue..$^{23}$ The laser wavelengths designated for disinfecting the tooth root canal system are: neodimium: yttrium aluminium garnet (Nd:YAG) $1064 \mathrm{~nm}$, diode 635 to $980 \mathrm{~nm}$; erbium, chromium: yttrium scandium gallium garnet (Er,Cr:YSGG) $2780 \mathrm{~nm}$; erbium: yttrium aluminium garnet (Er:YAG) 2940 nm; carbon dioxide (CO2) 9600 and $10600 \mathrm{~nm}$; potassium titanyl phosphate (KTP) $532 \mathrm{~nm} .^{21}$

The absorption of different wavelengths of each kind of laser in biological components and chromophores like water, apatite minerals, and various pigmented substances (microorganisms) is responsible for the physical effect of these dental lasers on the tooth root canal system. Lasers with wavelengths of visible and near-infrared electromagnetic radiation like the diode, Nd:YAG, and KTP lasers are poorly absorbed in water and hydroxyapatite, thus having a deeper antimicrobial action in dentin. On the contrary, erbium lasers with mid-infrared wavelengths are highly absorbed in water and hydroxyapatite, thus presenting a superficial effect on dentin walls. They can also be used for the removal of the layer and disruption of intracanal biofilms. ${ }^{24}$

The potential of the diode laser for soft tissue surgeries has been studied by many. On the contrary, minimal application of the same has been studied in the antibacterial activity against the root canal bacterium. The diode laser uses the solid semiconductor of aluminum gallium arsenide as an active medium operating in the near-infrared spectral region, between 808 and 980 $\mathrm{nm} .^{35,36}$

The penetration of diode laser irradiation to a depth of up to $1000 \mu \mathrm{m}$ into dentinal tubules could be responsible for its strong bactericidal effect. On the other hand, chemical disinfectants can only reach up to $100 \mu \mathrm{m}$ into the surrounding dentinal tubules, whereas the bacteria can penetrate and remain protected over $1000 \mu \mathrm{m}$ in the deeper layers of dentin. ${ }^{19,20}$

In an earlier study conducted on the extracted human teeth which were infected experimentally with E. faecalis, the effects of a high-power diode laser were analyzed and an average decrease in microorganisms (99.91\%) was observed when laser irradiation wasdone. ${ }^{37} 84.2 \%$ disinfection of the root canal after diode laser irradiation was achieved in this study. A similar study showed that diode laser irradiation gave greater disinfection of up to $100 \%$ in deep radicular dentin in the parameters and samples tested. ${ }^{38}$ However, in this study, among all the samples tested, CHX showed maximum percentage reduction of microorganisms.

An in vitro study compared the efficacy of the Nd:YAG, the diode, the Er:YAG, and the Er,Cr:YSGG laser in reducing the number of Escherichia coli and E. faecalis in the root canal dentin of human teeth. It was seen that all laser systems were capable of significant reductions of E. coli or E. faecalis. However, only the diode and Er:YAG lasers were capable of complete eradication of E. faecalis to a significant extent in the parameters used. ${ }^{35}$

Even though lasers manifest significant antimicrobial action, the thermal effect is the most important point to be considered while using the laser for root canal disinfection. A rise in temperature to a critical level could have adverse effects on the surrounding tissues of the tooth. An increase in temperature by approximately $10^{\circ} \mathrm{C}$ and treatment duration of $1 \mathrm{~min}$. can cause irreversible injury to the periodontal tissues. ${ }^{36}$ Gutknecht et al demonstrated that diode laser irradiation for 5 seconds, with 10 seconds of resting time, should be considered to avoid a temperature rise to an undesired level. ${ }^{39}$ Schoop et al also drew similar conclusions that a diode laser showed the lowest temperature increases compared with other laser devices and was suitable for the disinfection of root canals. $^{35}$

A pilot experiment reported that a $2.0 \mathrm{~W}$ diode laser was efficient in removing the smear layer on human primary teeth while avoiding dentinal melting. ${ }^{40}$ In our study, to avoid any thermal effects, the diode laser irradiation was performed with an output of $1.0 \mathrm{~W}$ for 5 seconds followed by a 20 -second interval at a wavelength of $980 \mathrm{~nm}$.

In the present study, root canal disinfection with chlorhexidine, sodium hypochlorite and the laser was found to be effective in reducing colony counts of all the species of bacteria found in the pre-disinfection sample. A decrease in colony counts was also seen in the saline group but was less than other groups.

Primary teeth root canals exhibit a wide bacterial variation marked by a polymicrobial endodontic infection, the same as permanent teeth. ${ }^{41} 93.5 \%$ aerobic microorganisms in a total sample of 29 human primary teeth with chronic periapical lesions and necrotic pulp were found by Pazelli et $\mathrm{al}^{12} S$. aureus, E. faecalis, and E. coli isolated from the root canals of 70 primary teeth were found in another recent clinical trial. ${ }^{13}$ In this study, E. coli was the most prevalent bacteria (20\%), followed by Staphylococcus species (19\%), E. faecalis (17\%) and Streptococcus species(16\%).

E. faecalis, a facultative gram-positive anaerobic coccus, is a widely known endodontic pathogen. It is routinely found in the root canals of teeth related to endodontic failures. It is also unaffected by the interappointment medicaments like calcium hydroxide. It can also reside in the root canal system as isolated single specie even in the absence of any other supportive micro-organisms. $E$. faecalis under particular conditions can infect the whole length of the dentinal tubules within a few days. Thus, it is paramount to eliminate these bacteria from the tooth root canals. ${ }^{14}$

In some of the previous studies, ${ }^{25,26,37,38}$ E. faecalis was consistently isolated from the teeth with chronic periapical infections or treatment failures due to reinfections. Among the samples chosen for this study, 17\% showed the presence of $E$. faecalis irrespective of the diagnosed 
pulpal pathology.

The findings of the present study should be considered in the light of the limitations of the study design. The samples taken for bacterial examination were collected from the root canal; however, bacteria may harbor deep inside the dentinal tubules and also the various anatomical complexities within the canal. Moreover, as it is known that the laser emits a unidirectional beam which travels in a straight line from the optical fiber tip, it is hard to achieve equal irradiation of the whole root canal dentin surface. ${ }^{24}$ This would be a probable reason why diode laser disinfection did not show a statistically significant reduction in the CFU counts over the other irrigants.

Additional research and clinical experiments are required to add more scientific evidence and clinical outcomes to construct a regime which can be reproduced in the endodontic treatment of human primary teeth.

\section{Conclusion}

Based on the results, observations and statistical analysis, the following conclusions can be made:

1. Chlorhexidine, $1 \%$ sodium hypochlorite and laser irradiation succeeded in significantly reducing the root canal microbial count of all the species of bacteria found in the pre-disinfection sample.

2. Diode laser irradiation may be used as an alternative to the existing protocols for root canal disinfection in human primary teeth. However, further clinical trials with the use of the diode laser in primary teeth with a larger sample size are warranted.

\section{Ethical Considerations}

This clinical trial was approved by the Institutional Ethics Committee (IEC/PEDO/48/13). The study objectives were fully described to the parents/accompanying guardians of children, who signed a written informed consent form authorizing their child's enrolment in the study.

\section{Conflict of Interests}

The authors declare no conflict of interest.

\section{References}

1. Gomes BP, Ferraz CC, Vianna ME, Berber VB, Teixeira FB, Souza FJ. In vitro antimicrobial activity of several concentrations of sodium hypochlorite and chlorhexidine gluconate in the elimination of Enterococcus faecalis. Int Endod J. 2001;34(6):424-8. doi:10.1046/j.13652591.2001.00410.x.

2. Sundqvist G. Ecology of root canal flora. J Endod. 1992;18(9):427-30. doi:10.1016/S0099-2399(06)80842-3.

3. Prabhakar AR, Chandrashekar Y, Agarwal S, Basappa N. Antimicrobial effects of laser-assisted photodynamic therapy in pediatric endodontic treatment: a new clinical horizon. Int J Laser Dent. 2013;3(3):77-81. doi:10.5005/jpjournals-10022-1042.

4. Ahmed HMA. Anatomical challenges, electronic working length determination and current developments in root canal preparation of primary molar teeth. Int Endod J. 2013;46(11): 1011-22. doi: 10.1111/iej.12134.

5. Gupta M, Mishra P, Srivastava R, Jyoti B. Cone beam computed tomography: A new vision in dentistry. Digit Med. 2015;1(1): 7-16. doi:10.4103/2226-8561.166361.

6. Silva Léa AB da, Nelson-Filho P, Faria G, de Souza-Gugelmin MCM, Ito IY. Bacterial profile in primary teeth with necrotic pulp and periapical lesions. Braz Dent J. 2006;17(2):144148. doi:10.1590/S0103-64402006000200012.

7. Marsh SJ, Largent MD. A bacteriological study of the pulp canals of infected primary molars. J Dent Child. 1967;34(6):460-470.

8. Cohen MM, Joress SM, Calisti LP, Mass B. Bacteriologic study of infected deciduous molars. Oral Surg Oral Med Oral Pathol. 1960;3: 1382-1386. doi:10.1016/00304220(60)90303-0.

9. Tomic-Karovic K, Jelinek E. Comparative study of the bacterial flora in the surroundings, the root canals and sockets of deciduous molars. Int Dent J. 1971;21(3):375388.

10. Chandwani M, Chandak S. Assessment of facultative anaerobes from the root canals of deciduous molars: An in vivo study. J Dent Res Dent Clin Dent Prospects. 2017;11(2):96-100. doi: 10.15171/joddd.2017.018.

11. Vineet RV, Nayak M, Kotigadde S. Association of endodontic signs and symptoms with root canal pathogens: A clinical comparative study. Saudi Endod J. 2016;6(2):826. doi: 10.4103/1658-5984.180621.

12. Pazelli LC, Freitas AC, Ito IY, Souza-Gugelmin MCM, Medeiros AS, Nelson-Filho P. Prevalence of microorganisms in root canals of human deciduous teeth with necrotic pulp and chronic periapical lesions. Pesqui Odontol Bras. 2003;17(4):367-71.

13. Verma MK, Pandey RK, Khanna R, Agarwal J. The antimicrobial effectiveness of 25\% Propolis extract in root canal irrigation of primary teeth. J Indian Soc Pedod Prev Dent. 2014;32(2):120-4. doi: 10.4103/0970-4388.130786.

14. Suresh BS, Shailaja S. Endodontic microflora- a review. J Oral Health Comm Dent. 2014;8(3): 160-165. doi: 10.5005/ johcd-8-3-125.

15. Fouad AF, Zerella J, Barry J, Spangberg LS. Molecular detection of Enterococcus species in root canals of therapy resistant endodontic infections. Oral Surg Oral Med Oral Pathol Oral Radiol Endod. 2005;99(1):112-118. doi:10.1016/j.tripleo.2004.06.064.

16. Cogulu D, Uzel A, Oncag O, Aksoy SC, Eronat C. Detection of Enterococcus faecalis in necrotic teeth root canals by culture and polymerase chain reaction methods. Eur J Dent 2007;1(4);216-221.

17. Venghat S, Hegde $M$, Shetty C. Irrigants used in endodontics. Int J Curr Microbiol App Sci. 2014;3(3):126132.

18. Mohammadi Z, Abbott PV. The properties and applications of chlorhexidine in endodontics. Int Endod J. 2009;42(4): 288-302. doi: 10.1111/j.1365-2591.2008.01540.x.

19. Castelo-Baz P, Martín-Biedma B, Ruíz-Piñón M, RivasMundiña B, Bahillo J, Seoane-Prado R, et al. Combined sodium hypochlorite and $940 \mathrm{~nm}$ diode laser treatment against mature E. Faecalis biofilms in vitro. J Lasers Med Sci. 2012;3(3):116-21. doi:10.22037/jlms.v3i3.3074.

20. Asnaashari M, Asnaashari N. Clinical application of 810 
$\mathrm{nm}$ diode laser and low-level laser therapy for treating an endodontic problem. J Lasers Med Sci. 2011;2(2):82-86. doi:10.22037/jlms.v2i2.2288.

21. Asnaashari M, Safavi N. Disinfection of contaminated canals by different laser wavelengths, while performing root canal therapy. J Lasers Med Sci. 2013;4(1):8-16. doi:10.22037/jlms.v4i1.3869.

22. Preethee T, Kandaswamy D, Arathi G, Hannah R. Bactericidal effect of the $908 \mathrm{~nm}$ diode laser on Enterococcus faecalis in infected root canals. J Conserv Dent. 2012;15(1):46-50. doi: 10.4103/0972-0707.92606.

23. Plotino G, Grande NM, Mercade M. Photodynamic therapy in endodontics. Int Endod J. 2019;52(6):760-774. doi: 10.1111/iej.13057.

24. Jurič IB, Anić I. The Use of lasers in disinfection and cleanliness of root canals: a review. Acta Stomatol Croat. 2014;48(1):6-15. doi: 10.15644/asc48/1/1.

25. Safan A, Youssef T, Zaazou MH. Antibacterial effect of silver and gold nanoparticles and diode laser against Lactobacillus acidophilus bacteria. Int J Adv Res. 2014;2(8):34-38.

26. Kaiwar A, Usha H L, Meena N, Ashwini P, Murthy CS. The efficiency of root canal disinfection using a diode laser: in vitro study. Indian J Dent Res. 2013(1); 24:14-18. doi: 10.4103/0970-9290.114916.

27. Mohammadi Z. Sodium hypochlorite in endodontics: an updated review. Int Dent J. 2008;58(6): 329-341. doi:10.1111/j.1875-595X.2008.tb00354.x.

28. Peters OA, Scheonenberger K, Laib A. Effects of four Ni-Ti preparation techniques on root canal geometry assessed by micro-computed tomography. Int Endod J. 2001;34(3):221230. doi:10.1046/j.1365-2591.2001.00373.x.

29. Siqueira JF, Rôças IN, Favieri A, Lima KC. Chemomechanical reduction of the bacterial population in the root canal after instrumentation and irrigation with $1 \%, 2.5 \%$, and 5.25\% sodium hypochlorite. J Endod. 2000;26(6): 331-334. doi:10.1097/00004770-200006000-00006.

30. Afzal A, Gopal VR, Pillai R, Jacob AS, U-Nu S, Shan S. Antimicrobial activity of various irrigants against $\mathrm{E}$. faecalis biofilm: an in vitro study. J Interdiscip Den. 2013;3(2):103108. doi:10.4103/2229-5194.126872.

31. Haapasalo M, Shen Y, Wang Z, Gao Y. Irrigation in endodontics. Br Dent J. 2014;216(6): 299-303. doi: 10.1038/ sj.bdj.2014.204.
32. Elakanti S, Cherukuri G, Rao VG, Chandrasekhar V, Rao AS, Tummala M. Comparative evaluation of antimicrobial efficacy of QMixTM 2 in 1, sodium hypochlorite, and chlorhexidine against Enterococcus faecalis and Candida albicans. J Conserv Dent. 2015;18(2):128-31. doi: 10.4103/0972-0707.153067.

33. Luddin $\mathrm{N}$, Ahmed HMA. The antibacterial activity of sodium hypochlorite and chlorhexidine against Enterococcus faecalis: A review on agar diffusion and direct contact methods. J Conserv Dent. 2013;16(1):9-16. doi: 10.4103/0972-0707.105291.

34. American Academy of Pediatric Dentistry. Policy on the use of lasers for pediatric dental patients. Oral Health Policies. 2017;40(6):95-97.

35. Schoop U, Kluger W, Moritz A, Nedjelik N, Georgopoulos A, Sperr W. Bactericidal effect of different laser systems in the deep layers of dentin. Lasers Surg Med. 2004;35(2):111116. doi:10.1002/lsm.20026.

36. Dai S, Xiao G, Dong N, Liu F, He S, Guo Q. Bactericidal effect of a diode laser on Enterococcus faecalis in human primary teeth-an in vitro study. BMC Oral Health. 2018;18(1):154. doi: 10.1186/s12903-018-0611-6.

37. Moritz A, Gutknecht N, Goharkhay K, Schoop U, Wernisch J, Sperr W. In vitro irradiation of infected root canals with a diode laser: Results of microbiologic, infrared spectrometric, and stain penetration examinations. Quintessence Int. 1997;28(3):205-209.

38. de Souza EB, Cai S, Simionato MR, Lage-Marques JL. High-power diode laser in the disinfection in depth of the root canal dentin. Oral Surg Oral Med Oral Pathol Oral Radiol Endod. 2008;106(1):e68-e72. doi: 10.1016/j. tripleo.2008.02.032.

39. Gutknecht N, Franzen R, Meister J, Vanweersch L, Mir M, Temperature evolution on human teeth root surface after diode laser assisted endodontic treatment. Lasers Med Sci. 2005; 20(2):99-103. doi:10.1007/s10103-005-0347-9.

40. Dai SS, Xiao G, Zhang L, Guo QY. The cleaning effect of diode laser on smear layer on root canals of primary teeth. J Oral Sci Res. 2016;32(7):742-745.

41. Ruviére DB, Leonardo MR, da Silva LA, Ito IY, Nelson-Filho P. Assessment of the microbiota in root canals of human primary teeth by checkerboard DNA-DNA hybridization. J Dent Child (Chic). 2007;74(2):118-23. 